\title{
LONG-TERM MONITORING OF WATER DYNAMICS IN THE SAHEL REGION USING THE MULTI-SAR-SYSTEM
}

\author{
A. Bertram ${ }^{\text {a, b }}$, A. Wendleder ${ }^{\text {a }}$, A. Schmitt ${ }^{\text {a }}$, and M. Huber ${ }^{\mathrm{a}}$ \\ ${ }^{a}$ German Aerospace Center, German Remote Sensing Data Center, Land Surface, 82234 Wessling, Germany - \\ (Anna.Wendleder, Andreas.Schmitt, Martin.Huber)@dlr.de \\ ${ }^{\mathrm{b}}$ Sachverständigenbüro für Luftbildauswertung und Umweltfragen (SLU), 81243 Munich, Germany - Adina.Bertram@dlr.de
}

Commission VIII, WG VIII/4

KEY WORDS: SAR, Geocoding, Kennaugh, Sahel Region, Water Dynamics, Long-term Monitoring

\begin{abstract}
:
Fresh water is a scarce resource in the West-African Sahel region, seasonally influenced by droughts and floods. Particularly in terms of climate change, the importance of wetlands increases for flora, fauna, human population, agriculture, livestock and fishery. Hence, access to open water is a key factor. Long-term monitoring of water dynamics is of great importance, especially with regard to the spatio-temporal extend of wetlands and drylands. It can predict future trends and facilitate the development of adequate management strategies. Lake Tabalak, a Ramsar wetland of international importance, is one of the most significant ponds in Niger and a refuge for waterbirds. Nevertheless, human population growth increased the pressure on this ecosystem, which is now degrading for all uses. The main objective of the study is a long-term monitoring of the Lake Tabalak's water dynamics to delineate permanent and seasonal water bodies, using weather- and daytime-independent multi-sensor and multi-temporal Synthetic Aperture Radar (SAR) data available for the study area. Data of the following sensors from 1993 until 2016 are used: Sentinel-1A, TerraSARX, ALOS PALSAR-1/2, Envisat ASAR, RADARSAT-1/2, and ERS-1/2. All SAR data are processed with the Multi-SAR-System, unifying the different characteristics of all above mentioned sensors in terms of geometric, radiometric and polarimetric resolution to a consistent format. The polarimetric representation in Kennaugh elements allows fusing single-polarized data acquired by older sensors with multi-polarized data acquired by current sensors. The TANH-normalization guarantees a consistent and therefore comparable description in a closed data range in terms of radiometry. The geometric aspect is solved by projecting all images to an earth-fixed coordinate system correcting the brightness by the help of the incidence angle. The elevation model used in the geocoding step is the novel global model produced by the TanDEM-X satellite mission. The advantage of the Multi-SAR-System is that it comprises ortho-rectification, radiometric enhancement, normalization and Kennaugh decomposition, independent from sensors, modes, polarizations or acquisition date of SAR data. In addition, optical satellite data can be included as well, to fill gaps where SAR data are missing due to the special normalization scheme. This kind of pre-processing is exclusively implemented at the Earth Observation Center of the German Aerospace Center in Oberpfaffenhofen, Germany. Therefore, the dynamic change of the open water of the Lake Tabalak could be classified over dry and rainy seasons and years, using different SAR data. The study provides a unique database and contributes to a better understanding of wetland systems in the Sahel region influenced by human pressure and climate change.
\end{abstract}

\section{INTRODUCTION}

The semi-arid to arid West-African Sahel region lacks of fresh water and is characterized by rainy and dry season. Especially the rainy season with two to four wet months is very short (Mahamane et al., 2012). Therefore, access to fresh water is a key factor, provided by wetlands. These areas concentrate and supply fresh water and nutrients, and are utilized by flora, fauna, human population, agriculture, livestock and fishery. Due to the utilization by different users and user groups wetlands are under pressure. The different user interests could cause conflicts, but also climate and land use change, desertification, socio-economic and demographic change are threatening these ecosystems. Therefore, the fresh water resource of wetlands in drylands is extremely important but damageable, particularly in terms of climate change with unreliable rainfall, floods and droughts.

Niger in the West-African Sahel region consists of about 1.000 isolated wetlands that are very valuable to different user groups, playing a major role for biodiversity and ecosystem services in general. An example for such an isolated inland wetland is Lake Tabalak, located in southwest Niger (Figure 1). In 2004 it became a Ramsar site of international importance as one of the most significant ponds in Niger and a habitat for waterfowl, called 'La Mare de Tabalak'. Ramsar sites have to be representative, rare or unique wetland types and need to fulfil some of eight criteria of biological diversity (Bureau de la Convention de Ramsar, 2004). Nevertheless, Brouwer (2014) and Brouwer et al. (2014) showed that the increasing population, agriculture and fish production increase the pressure on this ecosystem. Seasonally passing pastoralists, as well as the population of water birds decreased over time. Also planned irrigation projects will dry out the lake. This leads to degradation for all uses.

Therefore multi-temporal monitoring of such wetlands is very important, especially with regard to the spatio-temporal extent of wetlands and drylands. It can predict future trends and facilitate the development of adequate management strategies. Water as resource will run short. Due to the wetlands high dynamic, inaccessibility, and extend only remote sensing can achieve consistent monitoring. It is possible to observe large areas, and do long-term monitoring, using sensors that fit best for the research area and the interested time-series. Synthetic aperture radar (SAR) data is useful to study wetlands. The big 
advantage in comparison to optical data is its weather- and daytime-independency. This is important especially during the rainy season. Nevertheless, only a few studies deal with wetland monitoring in the Sahel region, using optical and/or SAR data (e.g., Moser et al., 2016; Gessner et al., 2015; Moser et al., 2014). In addition only short term data (e.g., 2 years) are utilized, generally.

In this study data of the following sensors with different resolutions and polarizations from 1993 until 2016 are used: Sentinel-1A, TerraSAR-X (TSX), ALOS PALSAR-1/2, Envisat ASAR, RADARSAT-1/2, and ERS-1/2. They are processed using the Multi-SAR-System, comprising ortho-rectification, radiometric calibration, normalization, Kennaugh decomposition, and further image enhancement. The MultiSAR-System unifies all scenes to a consistent format.

Compared to previous studies the use of nine sensors for the monitoring of wetlands or open water bodies is unique. Santoro et al. (2015), Westra et al. (2010), and Liebe et al. (2009) for example used only data of Envisat ASAR. But a combination of two to three different sensors is not exceeded, regardless of whether SAR data alone or combined with optical data were utilized (e.g., Bwangoy et al., 2010; Munyaneza et al., 2009; Li and Chen, 2005).

The main objective of the study is to do a long-term monitoring of the water dynamics of Lake Tabalak to delineate permanent and seasonal water bodies, using weather- and daytimeindependent multi-sensor and multi-temporal SAR data processed with the Multi-SAR-System. So the change of the water bodies can be investigated over several years and decades.

\section{MATERIAL}

\subsection{Study area}

Lake Tabalak is located in the semi-arid to arid south-west of Niger $\left(15^{\circ} 04^{\prime} \mathrm{N} / 5^{\circ} 38^{\prime} \mathrm{E}\right)$ near the city Tahoua, $400 \mathrm{~m}$ above sea level. The location of the lake can be seen in Figure 1. The isolated wetland is part of the Sahelian Acacia Savanna, dominated by bare and sparsely vegetated areas, with an annual rainfall of about $390 \mathrm{~mm}$, falling during the rainy season from July to September (Mahamane et al., 2012; Olson et al., 2001). Dependent on the rainy season parts of the lake are permanent, varying between 1150 ha and 600 ha, or can dry up completely (Brouwer et al., 2014). Thus, it is enormously dynamic. The lake is part of the Ramsar wetland 'La mare de Tabalak', which was founded in 2004. The wetland is of international importance, one of the most significant ponds in Niger and a refuge for waterbirds like stilts and pelicans. It helps to control floods and to recharge groundwater. The population (42.000 in 2001 ), living in the lake's catchment area in about 60 villages, are dependent on its water resources, the fish, and agricultural land associated with the wetland (Dekens et al., 2013; Bureau de la Convention de Ramsar, 2004).

In the beginning of the 1990 s the waterfowl consists of about 48 species. There were a few trees along the northern end of the lake that were cut some years later. All large mammals had disappeared. The lakes surroundings were covered by vegetable gardens $(20 \%)$ and were accessed by livestock $(80 \%)$. In recent years human activities and population increased. Thus, the number of waterbirds decreased a lot and almost all indigenous trees are gone, replaced e.g., by mango trees or eucalyptus. Market gardening and fish production is dominating, and there is only few access for livestock left (Brouwer, 2014; Brouwer et al., 2014).

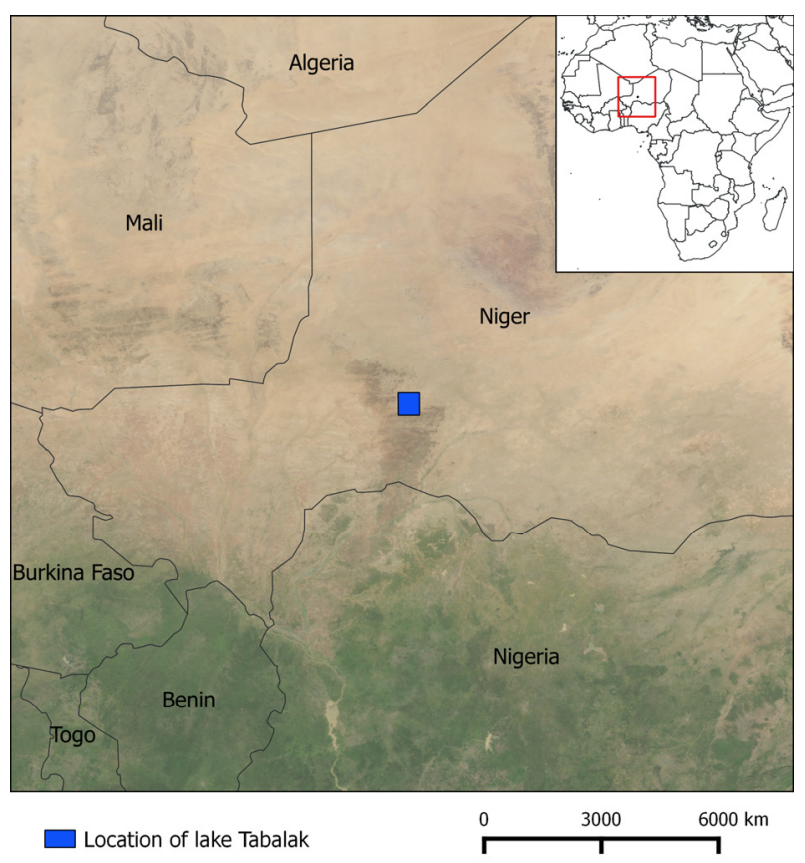

Figure 1. The study area Lake Tabalak, Niger, West Africa.

\subsection{Data}

In the following the different SAR data used in the study are presented.

\subsubsection{Digital Elevation Model}

For the geocoding process the global digital elevation model derived from interferometric X-band SAR acquisitions of the TanDEM-X mission, with a high-resolution of about $12 \mathrm{~m}$, is used (Hueso González et al., 2012). The DEM-tile includes combined acquisitions from September 2011 until November 2014. The new DEM comes into operation to use a DEM with the best available resolution. It is not necessary to process SAR data from the 1990s with an older, and therefore less accurate DEM, because the elevation did not change.

\subsubsection{SAR data}

To do the long-term monitoring of Lake Tabalak, SAR data of the following sensors from August 1993 until March 2016 are used: Sentinel-1A, TSX, ALOS-PALSAR-1/2, Envisat ASAR, RADARSAT-1/2, and ERS-1/2. A summary of the sensor characteristics used in the study is given in Table 1 .

With these data it is possible to investigate the lakes water dynamics of different decades, years, and seasons. Although one has to take in account that there are years without data and for some sensors there is only one scene per year available, as the coverage of SAR data in West-Africa still is improvable. The used data with acquisition date are shown in Figure 2.

\section{METHODOLOGY}

\subsection{Multi-SAR-System}

Primarily, the SAR data of Sentinel-1A, TSX, ALOS-PALSAR$1 / 2$, Envisat ASAR, RADARSAT-1/2, and ERS-1/2 are all processed with the Multi-SAR-System. This pre-processing system is exclusively implemented at the Earth Observation Center of the German Aerospace Center, Germany, and contains nine production steps (Figure 3). It comprises, among others, an ortho-rectification, the Kennaugh decomposition, 
Table 1. Characteristics of the used SAR sensors.

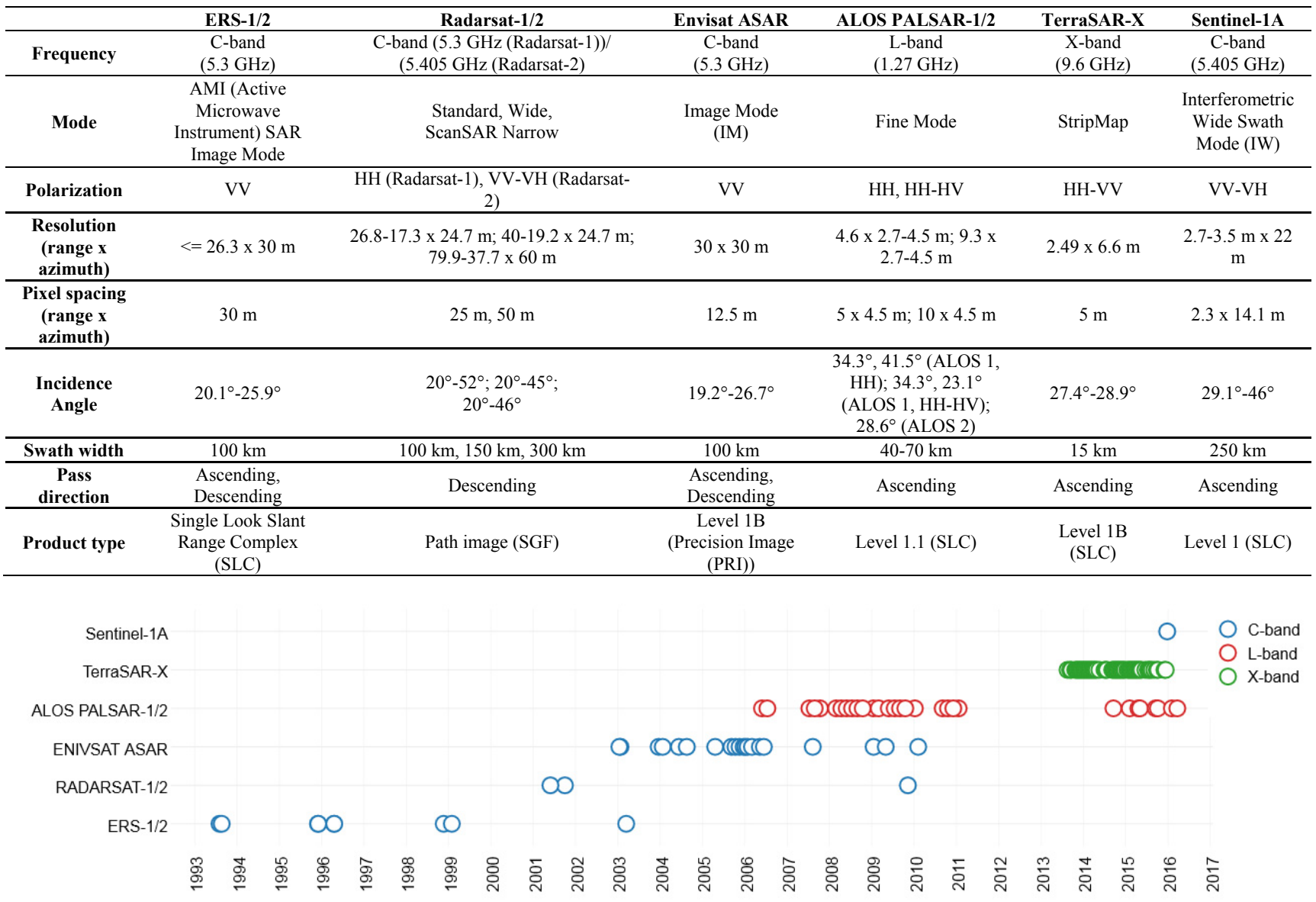

Figure 2. All processed data sorted by sensors and acquisition time from August 1993 to March 2016.

multi-looking, radiometric calibration and image enhancement, which are explained in detail in the following subchapters (Schmitt et al., 2015; Huber at al., 2004).

The Multi-SAR-System can be used for the processing of all abovementioned SAR data in level 1 (focussed, slant range, single-look, complex) independent of their geometric, radiometric and polarimetric resolution. The main benefit of this system is that despite divers input data formats and interfaces, the same workflow and the same parameter configuration file can be used. The final result is a SAR image in level 2 represented in a consistent data format.

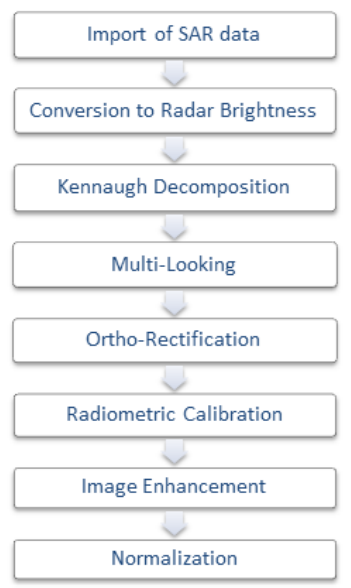

Figure 3. Production steps of the Multi-SAR System

\subsubsection{Import of metadata}

Every SAR image is delivered in its specific data format and file structure, for example ERS-1/2 data in the binary CEOS format, which is the formerly product format standard, or the Sentinel-1A image in geotiff-format and its metadata in xmlfile. In the first step, the SAR data are imported and converted to a consistent data structure and format in order to support a homogenous interface and consistent workflow for the following Multi-SAR-System.

\subsubsection{Conversion to radar brightness}

The intensity of each pixel is digitised and recorded as a digital number due to data storage. In order to obtain the original physically meaningful backscatter value it is necessary to convert the digital number to radar brightness. Therefore, the following equation can be used:

$$
\beta^{\boldsymbol{o}}=c \cdot(D N)^{2}=c \cdot\left(I^{2}+Q^{2}\right)
$$

where

$$
\begin{aligned}
& \beta^{o}=\text { the radar brightness (beta naught) } \\
& c=\text { the calibration factor } \\
& D N=\text { the digital number } \\
& I=\text { the real part of a complex image } \\
& Q=\text { the imaginary part of a complex image }
\end{aligned}
$$

The calibration factor is denoted in the metadata. Its value is processor and product type dependent and might even change between the different beams of the same product (Airbus Defence and Space, 2014). 


\subsubsection{Kennaugh Decomposition}

The Kennaugh matrix describes the polarimetric information and enables the interpretation of physical scattering mechanisms (e.g., double-bounce, surface- and volume scattering). It is comparable to the covariance and the coherence matrix. In contrast to other matrix representations, every Kennaugh element is a real number and thus, quite simple to handle. The Kennaugh matrix consists of ten elements: the first element $\mathrm{K}_{0}$ represents the total intensity and is available with any polarimetric combination; the remaining nine elements $\mathrm{K}_{1}$ to $\mathrm{K}_{9}$ are all intensity differences, whose numbers and availabilities depend on the polarization of the SAR acquisition. For example, in the case of dual-cross polarized data, the Kennaugh elements reduce to four independent elements $\mathrm{K}_{0}$, $\mathrm{K}_{1}, \mathrm{~K}_{5}$, and $\mathrm{K}_{8}$, whereas in the case of dual-co polarized data, the elements are reduces to $\mathrm{K}_{0}, \mathrm{~K}_{3}, \mathrm{~K}_{4}$, and $\mathrm{K}_{7}$. In the case of quad-pol, all ten Kennaugh elements are meaningful. Furthermore, the Kennaugh elements can be divided into three different groups: $\mathrm{K}_{1}, \mathrm{~K}_{2}$, and $\mathrm{K}_{3}$ describe the loss of polarization during scattering process, i.e., the intensity ratio between double bounce and surface intensity; $\mathrm{K}_{4}, \mathrm{~K}_{5}$, and $\mathrm{K}_{6}$ describe the diattenuation, i.e., the change of the relation between two amplitude values (for example between $\mathrm{HH}$ and $\mathrm{VV}) ; \mathrm{K}_{7}, \mathrm{~K}_{8}$, and $\mathrm{K}_{9}$ describe the phase change between doublebounce and surface scattering. Hence, independent of the polarization, sensor or wavelength, the Kennaugh decomposition enables the comparability and combination of different SAR data (Schmitt et al., 2015).

\subsubsection{Multi-looking}

The multi-looking has two main advantages. Firstly, it mitigates speckle due to constructive and destructive interferences between different backscattered signals from different ground targets. Especially above homogeneous areas, these interferences result in a grainy appearance of the image. Consequently, it improves the SAR image quality and it increases the capability to separate and to classify distributed targets (Moreira, 1991). Secondly, it produces square pixels on the output image. During the multi-looking step, a uniform number of looks is calculated and hence applied for the whole image. Therefore, different looks of one single image are averaged. The higher the number of looks is, the lower the spatial resolution, but the higher the radiometric accuracy. The adequate number of looks can be calculated from the incidence angle of the image, the original geometric resolution in slant range and azimuth, and the designated pixel spacing on ground (Schmitt et al., 2015).

Figure 4 shows the application of the multi-looking. The left image displays a one look image, whereas the right image displays the same subset multi-looked with 64 looks. On the one hand, originally very heterogeneous structures are blurred. On the other hand, the noise content over homogeneous area is decreased significantly. Therefore, the minimal look number is chosen at this point. All further noise reduction is performed in the image enhancement step later on.

\subsubsection{Ortho-rectification}

Due to the side looking geometry of SAR-systems undulated terrain is significantly distorted during the SAR mapping process. The most important and well-known local image distortions are foreshortening, layover and shadow (Schreier, 1993). The area is not seen by the radar. But also the range displacement effect needs to be considered that causes elevated features to be mapped in false range position - namely too closely to near range. These effects can be corrected during the ortho-rectification using a digital elevation model.

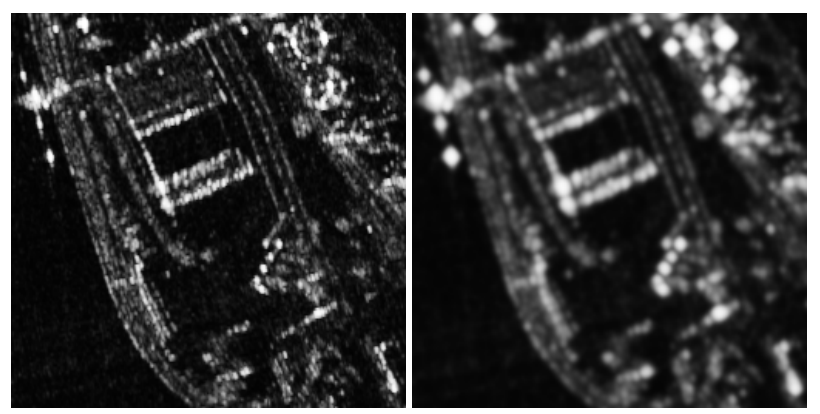

Figure 4. Subset of a TerraSAR-X spotlight acquisition over the harbor area of Mannheim-Ludwigshafen in Germany. For the left image only one look, whereas for the right image 64 looks are applied (Schmitt et al., 2015).

The digital elevation model is provided by the in-house Digital Elevation Model Data Base (DEM-DB). The DEMs of different sources, i.e., TanDEM-X, SRTM X-Band, SRTM C-Band, ASTER GDEM, Globe, etc., are stored in separate projects which enables the separate valuation as well as the fusion of different qualities and DEM sources.

\subsubsection{Radiometric Calibration}

The radiometric calibration is necessary to enable the intercomparison of SAR images acquired in different imaging geometries. The radar backscatter strength is defined as a ratio between the scattered and incident powers, whereas the backscatter coefficients are calculated by normalizing the calculated backscatter by a standard area. This area can be expressed in three different reference areas: (1) the slant range area which also referred to radar brightness or beta naught $\beta^{o}$, (2) the ground area which results in sigma naught $\sigma^{o}(3)$ the plane perpendicular to the slant range direction which delivers gamma naught $\gamma^{o}$. In Figure 5 all three reference areas are illustrated. The usage of radar brightness (beta naught) is advisable if the original radar measurement is preferred. The calculation of sigma and gamma naught reduces the effect of local topographic variations whereat sigma naught is usually used in flat terrain and gamma naught in hilly or mountainous terrain (Small, 2011). Both require knowledge about the illuminated area. Approximate solutions use the local incidence angle which is provided by the GIM (Geocoded Layover Shadow and Incidence Angle Mask) in order to estimate the surface ratios. The GIM layer is produced during the orthorectification and has consequently the same cartographic properties as the ortho-rectified SAR image with regard to output projection and cartographic frame (Huber et al., 2004; Raggam and Gutjahr, 2004; Meier et al., 1993).

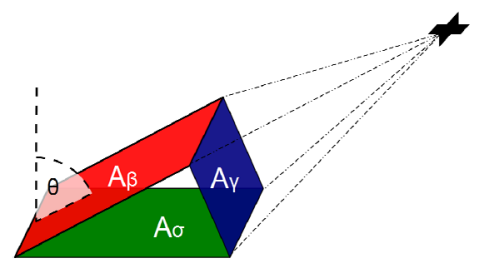

Figure 5. Three reference areas of SAR backscatter (Schmitt, 2012)

\subsubsection{Image Enhancement}

SAR data are known to include a high noise content showing both additive and multiplicative characteristics. Therefore, image enhancement is unavoidable in order to achieve smooth results. In most applications, standard speckle filtering 
algorithms with a fixed kernel size are used in order to reduce the influence of the multiplicative noise contribution. This is similar to the uniform multi-looking described before. We prefer a novel image enhancement approach called multi-scale multi-looking which has been developed especially for the enhancement of Kennaugh layers acquired by different SAR sensors (Schmitt et al., 2015).

The basic idea of this approach is to adapt the local number of looks to the image content. For instance, a higher look number might be appropriate in a homogeneous environment (e.g., water) while the minimal look number and therewith the maximum geometric resolution is necessary to adequately describe the single targets in a very heterogeneous environment (e.g., rock). The decision - which look number to use - is taken by the help of a novel perturbation-based noise model that combines both additive and multiplicative noise contributions in one and automatically adapts to the sensor and imaging mode characteristics via the delivered metadata. The result is a very smooth, but detail-preserving multi-looked SAR image representing the locally optimal trade-off between geometric resolution and radiometric accuracy.

In Figure 6 the benefit of the multi-scale multi-looking is clearly visible. On the left image, only one number of looks is adapted for the total intensity image. On the right image, the multi-scale multi-looking approach is applied, hence the number of looks varies and is locally adapted depending of corresponding structure. With an increasing number of looks, the noise decreases, the radiometric accuracy increases, and the homogeneous structures are now better perceptible and distinctive.

Future processor implementation will even support multi-scale and multi-directional multi-looking in order to improve the target shape approximation.
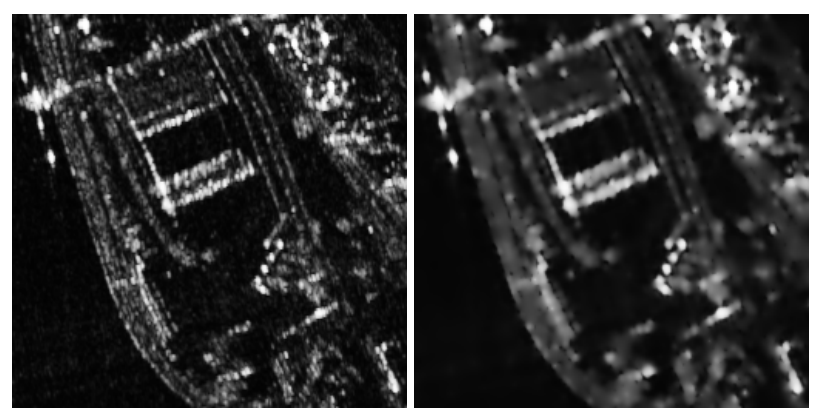

Figure 6. Subset of a TerraSAR-X spotlight acquisition over the harbor area of Mannheim-Ludwigshafen in Germany. For the left image only one number of looks is adapted, whereas for the right image multi-scale multi-looking is adapted (Schmitt et al., 2015).

\subsubsection{Normalization}

The last step is the normalization of the backscatter values in the output image. It comprises the scaling of the floating point values in linear scale to a closed value range from -1 to +1 , and the final conversion to integer values. The here applied sampling bases on the hyperbolic tangent function. Compared to other sampling methods, the image can be described in a finite value range using only a limited number of samples. Thus, image compression with negligible loss of information is enabled and the inter-comparison across sensors and imaging modes is assured at the same time. The values can directly be referred to $\mathrm{dB}$-values if wished by the user.

\subsection{Classification of the water mask}

To classify Lake Tabalak's open water all available 122 SAR scenes are processed using the Multi-SAR-System. For the radiometric calibration sigma nought is used, due to the flat terrain. As output only the first Kennaugh element $\mathrm{K}_{0}$ is chosen. The geocoded pixel spacing is selected to be 10 to $10 \mathrm{~m}$, and for the image enhancement multi-scale multi-looking comes into operation. In addition, the images are corrected for possibly remaining shifts, because of inaccuracies in the available orbit data. For convenience, the image values are transferred to the common unit $\mathrm{dB}$. For the detection of water the following $\mathrm{dB}$ thresholds depending to the different sensors are used: ERS-1/2: $-21 \mathrm{~dB}$; Radarsat-1/2: $-17 \mathrm{~dB}$; Envisat ASAR: $-10.5 \mathrm{~dB}$; ALOS PALSAR-1: $-20 \mathrm{~dB}$; ALOS PALSAR-2: -21 dB; Sentinel-1A: $17 \mathrm{~dB}$; TSX: $-18 \mathrm{~dB}$ (rainy season July to September), $-19 \mathrm{~dB}$ (beginning of dry season, Oktober to February), $-21 \mathrm{~dB}$ (dry season, March to June). Nevertheless, not all sensors are qualified to detect open water. In some scenes there is too much water classified, as dry sand also results in a very weak backscatter signal. Therefore, a mask for the maximum outline of Lake Tabalak is used.

\section{RESULTS AND DISCUSSION}

In the following the results of Lake Tabalak's water dynamics from August 1993 to March 2016 are shown and discussed: a time series of TSX data and a time series of all available and suitable SAR scenes of the above mentioned sensors.

Figure 7 illustrates the annual average of water presence derived from TSX data in the seasons 2013/2014 (21 scenes from 2013-08-17 to 2014-05-19) and 2014/2015 (26 scenes from 2014-07-02 to 2015-06-19). TSX was chosen because the data acquisition of two to three weeks is outstanding in comparison to the other sensors (see Figure 2). A season starts with the beginning of the rainy season in July and ends in the end of the dry season in June. Starting from the rainy season, the open water surface reduced until the end of the dry season. Only less than $1 / 4$ of the largest water extent is left. In both seasons the lower part has no connection to the middle part of the lake, all three parts dry out from south to north, the maximum water extend is in the beginning of September, and the minimum in the middle of May. In general season 2014/2015 was dryer. Thus, in June 2015 Lake Tabalak dried out completely. In Figure 8 only 97 suitable SAR scenes of 122 are combined, showing the average of water presence from 1993-08-22 to 2016-02-03, and the minimum (Envisat ASAR: 2005-04-20) and maximum (ALOS PALSAR: 2007-10-12) water extent of all used scenes. Although the minimum surface water area was in April 2005, the years with the second least water extend are from 2014 to 2016, which can be seen in Figure 9. Furthermore, the water extent in the 2000s is generally higher (max. and min.). In Figure 8 it is clearly visible that the surface water area decreased a lot during 1993 and 2016 (red to orange parts), especially at the south-east outline, and at the connections of the three parts of Lake Tabalak. In addition, one can see a dam in the south-west of the lake, build in the beginning of the time-series. Maybe it was constructed because of a decreased water level, to get more land for agricultural uses. Even, when the surface water area reduces during a season, agricultural fields follow the water. This is called dry-season cropping, dependent on the residual soil moisture. Areas not used in years with much rainfall can work as reinsurance whilst droughts (Brouwer, 2014). Furthermore, access of livestock decreased at Lake Tabalak. But during dry 
years the whole system could collapse, when the little water is used for other purposes. Also fishery is dependent do the rainy season. A drought in 1984 caused a low fish production in the following year (Brouwer, 2014). In addition, the effects of climate change with rising temperatures and extreme events like droughts and floods will have no positive impact on the area and will lead to growing pressure on the wetland. Dekens et al. (2013) showed that the lake and its increasing population $(2.7 \%$ per year) are very prone to droughts, resulting in a decreasing water level and food production. Only adequate participatory, national, and local management and development will help to cope with the situation at Lake Tabalak. Nevertheless, like Brouwer et al. (2014) demonstrated, it is unrealistic under these circumstances to bring back the high biodiversity the lake once had.

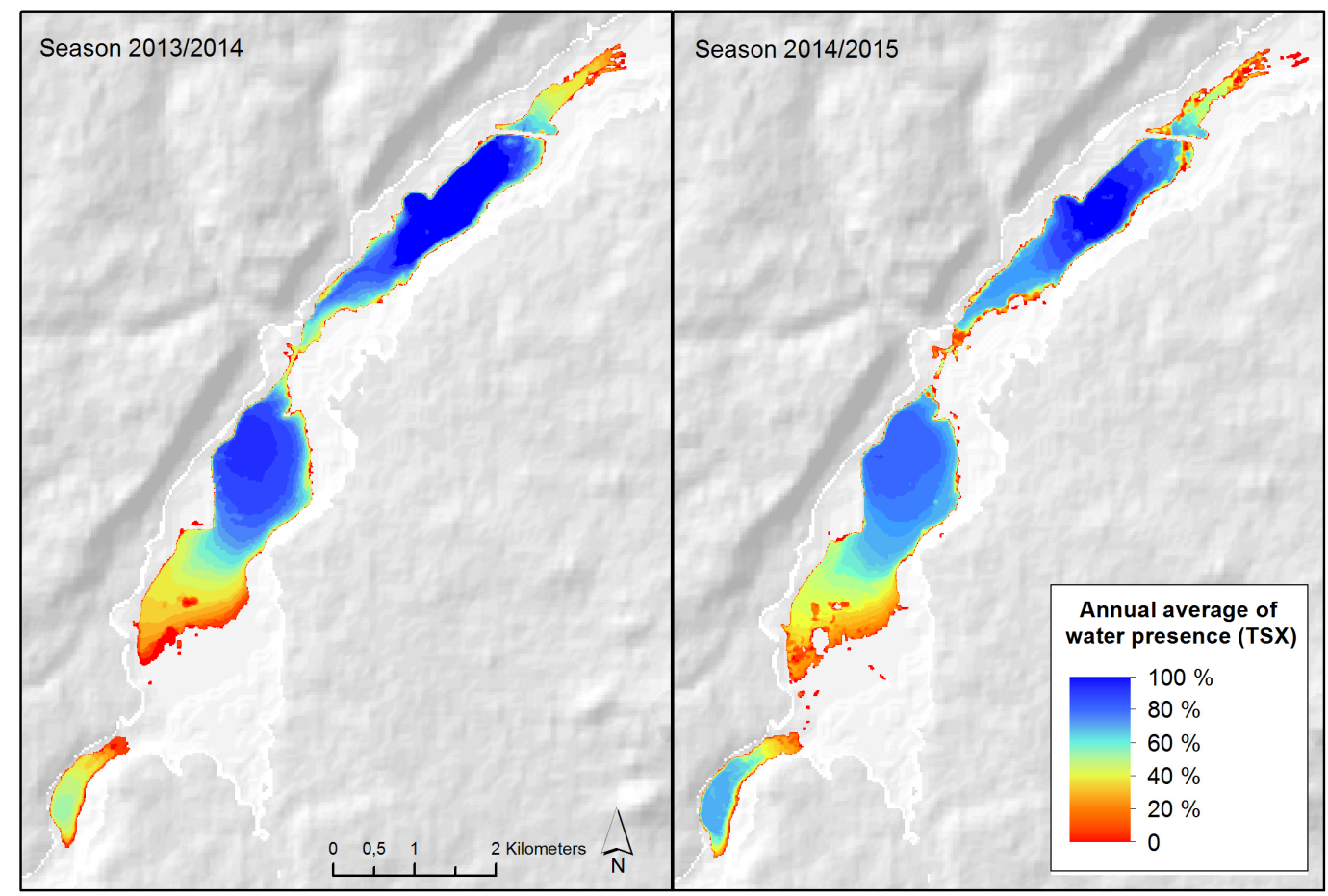

Figure 7. Annual average of water presence derived from TSX data in the seasons 2013/2014 (combination of 21 scenes from $2013-$ 08-17 to 2014-05-19, left) and 2014/2015 (combination of 26 scenes from 2014-07-02 to 2015-06-19, right) using the shaded relief from SRTM DEM.

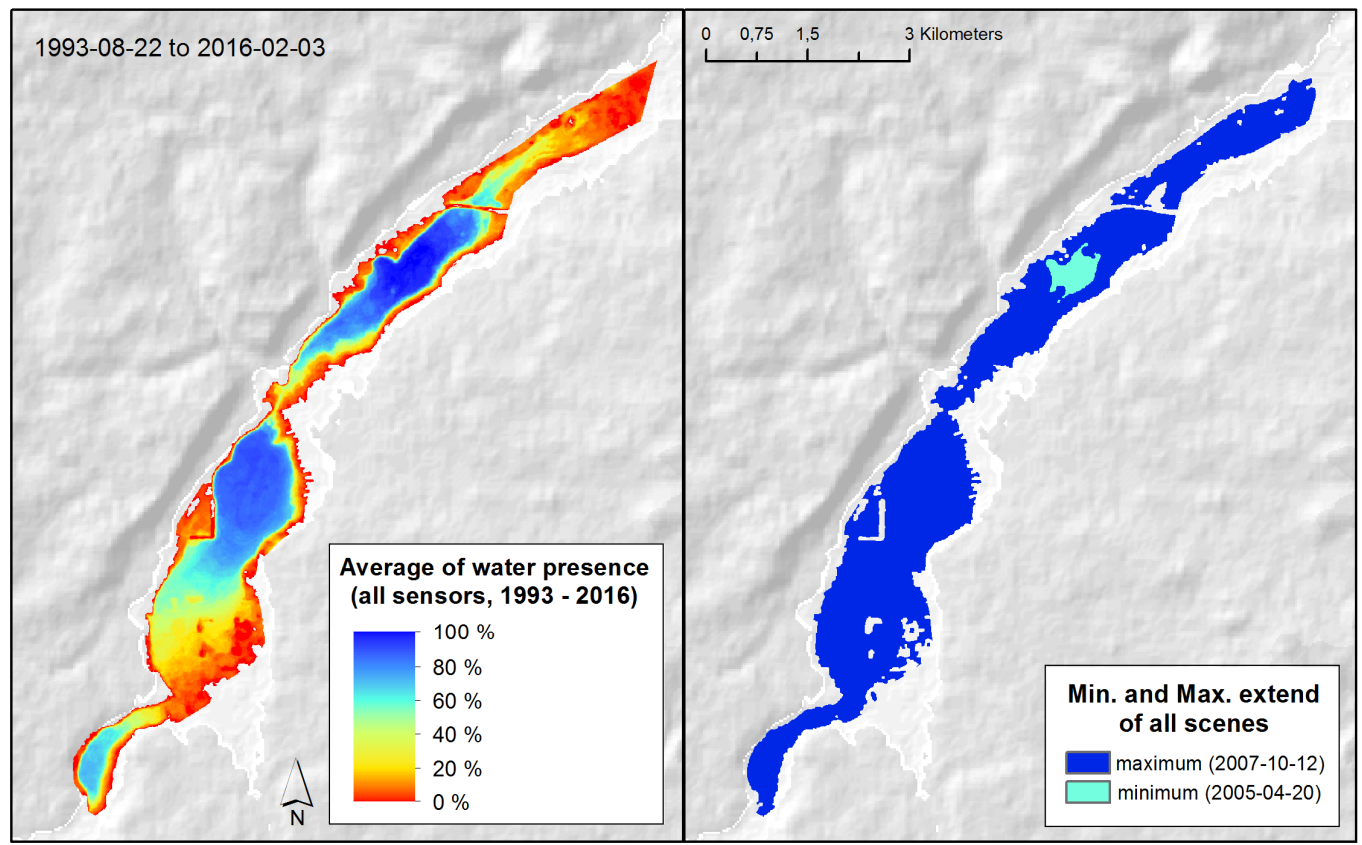

Figure 8. Average of water presence of 97 used scenes (1 ERS-1, 1 Radarsat-2, 10 Envisat ASAR, 28 ALOS PALSAR-1/2, 56 TSX, 1 Sentinel-1A) from 1993-08-22 to 2016-02-03 (left) and the minimum (2005-04-20) and maximum water extend (2007-10-12) of Lake Tabalak of these 97 scenes (right) using the shaded relief from SRTM DEM. 


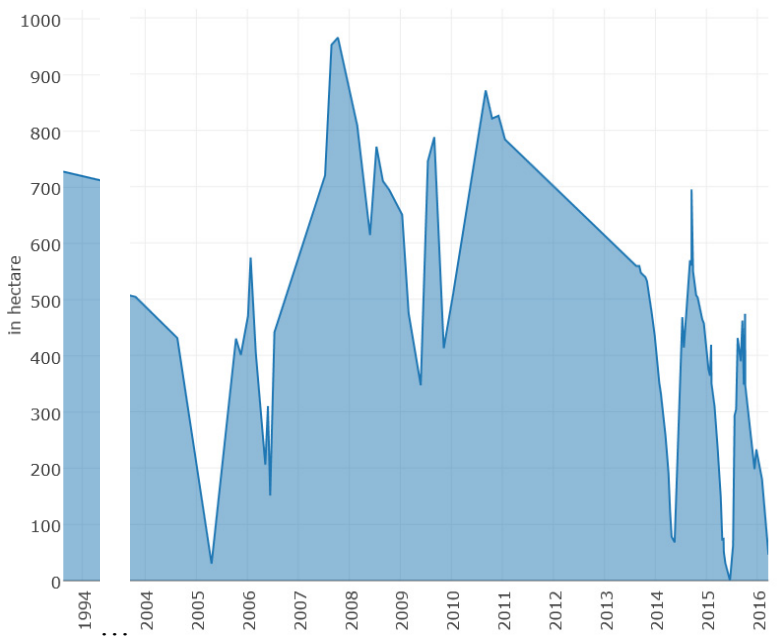

Figure 9. The water surface area in hectare of all 97 suitable SAR scenes from 1993 to 2016.

The main reason why 25 scenes are not suitable for the classification of open water is a misclassification of water. On the one hand Westerhoff et al. (2013) and O'Grady et al. (2011) mention the problem of wrong classifications due to low backscatter from non-flooded areas attenuating and absorbing the signal. This is the case especially in desert sands in the arid Sahel region. In this study this is a problem with ALOS PALSAR-1/2, Sentinel-1A, and Envisat ASAR data. Therefore, a mask was used, eliminating the wrong classified areas. On the other hand a misclassification of water is caused by an increased backscatter signal from the water surface from windinduced waves, called Bragg effect (Liebe et al., 2009; O'Grady et al., 2011). This scattering occurs especially over inland water bodies, in the used Envisat ASAR and ERS-1/2 data (see Figure 10) (e.g., Bartsch et al., 2012; Liebe et al., 2009). The outlines of the lake cannot be determined. In general, in C- and X-band wind and wave patterns are visible. That is why they are more suitable for sea applications. In contrast L-band support wetland inventory (Rosenqvist et al., 2007). Normally, the water surface of Lake Tabalak is free of vegetation, but in former years it could be possible that the high backscatter is also caused by vegetation. A scene is excluded, if more than $40 \%$ of the water surface has these effects. The round artifacts within the water in Figure 7 and 8 are Bragg effects, or perhaps vegetation. In addition, Radarsat- 1 could not be used, because of insufficient orbit accuracy.

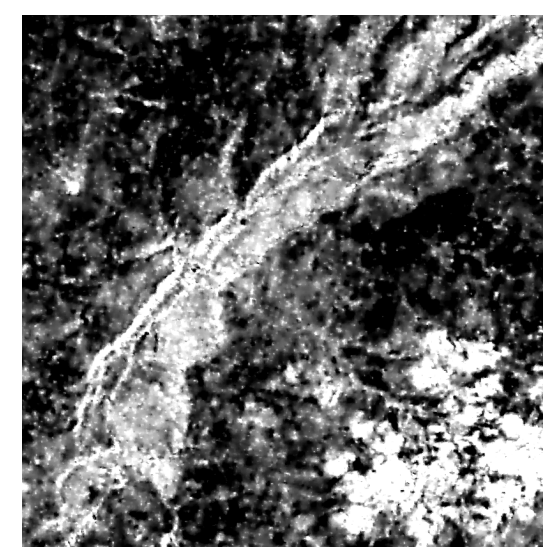

Figure 10. Bragg effect in ERS-2 data (1998-11-20). The water in the end of the rainy season has a very high backscatter signal.

\section{CONCLUSIONS}

This study demonstrates the successful use of different SAR data for doing a long-term monitoring of Lake Tabalak, a Sahelian Ramsar wetland. It is extremely important, as fresh water is a scarce resource in the West-African Sahel region, influenced by rainy and dry season. All available SAR data for the study area from 1993 to 2016 were successfully processed with the Multi-SAR-System, unifying all scenes to a consistent format. Although not all available data are suitable to classify the water surface area, due to Bragg effects and increased backscatter signals of water, the study is outstanding, showing the reduction of water level over more than two decades. Especially in recent years the decreased water extend in comparison to former years is visible. This development is caused by the human population growth, increased agriculture and fish production, the loss of biodiversity, effects of climate change, irrigation projects, and malfunctioning management strategies. The study contributes to a better understanding of wetlands in the Sahel region influenced by human pressure and climate change.

\section{ACKNOWLEDGEMENTS}

The authors acknowledge the European Space Agency (ESA) for the delivery of Envisat ASAR- [2003-2010], ERS-1/2[1993-2003], and Radarsat-1/2 data [2001-2009] (Proposal Nr. 31909). TSX data are provided by the German Aerospace Center (DLR) (Proposal Id: MTH0771) [2013-2015], ALOSPALSAR data by JAXA and METI (PI No. 1137) [2006-2016], and Copernicus Sentinel data [2015] for Sentinel-1A data.

\section{REFERENCES}

Airbus Defence and Space, 2014. Radiometric Calibration of TerraSAR-X Data - Beta Naught and Sigma Naught Coefficient Calculation. Friedrichshafen, Germany (TSXXITD-TN-0049-radiometric_calculations_I3.99.doc).

Bartsch, A., Trofaier, A.M., Hayman, G., Sabel, D., Schlaffer, S., Clark, D.B., Blyth, E., 2012. Detection of open water dynamics with ENVISAT ASAR in support of land surface modelling at high latitudes. Biogeosciences, 9, pp. 703-714.

Brouwer, J., 2014. Are the Most Valuable Resources in Dryland Areas Isolated Wetlands? GRF Davos Planet@Risk, 2(1), pp. $47-56$.

Brouwer, J., Abdoul Kader, H.A., Sommerhalter, T., 2014. Wetlands help maintain wetland and dryland biodiversity in the Sahel, but that role is under threat: an example from 80 years of changes at Lake Tabalak in Niger. Biodiversity, 15(2-3), pp. 203-219.

Bureau de la Convention de Ramsar, 2004. Fiche descriptive sur les zones humides Ramsar (FDR). Gland, https://rsis.ramsar.org/RISapp/files/RISrep/NE1494RIS.pdf (16.12.2015).

Bwangoy, J.R.B., Hansen, M.C., Roy, D.P., Grandi, G. De, Justice, C.O., 2010. Wetland mapping in the Congo Basin using optical and radar remotely sensed data and derived topographical indices. Remote Sensing of Environment, 114, pp. 73-86. 
Dekens, J., Nazoumou, Y., Zamudio Trigo, N.A., Adamou, M.M., Hambally, Y., McCandless, M., 2013. Gestion durable des zones humides face aux risques climatiques au Niger: Le cas de la mare de Tabalak. Programme des Nations Unies pour le développement (PNUD) et le Bureau de la prévention des crises et du relèvement (BCPR), New York, pp. 1-57.

Gessner, U., Machwitz, M., Esch, T., Tillack, A., Naeimi, V., Kuenzer, C., Dech, S., 2015. Multi-sensor mapping of West African land cover using MODIS, ASAR and TanDEM$\mathrm{X} /$ TerraSAR-X data. Remote Sensing of Environment, 164, pp. 282-297.

Huber, M., Hummelbrunner, W., Raggam, J., Small, D., Kosmann, D., 2004. Technical aspects of Envisat-ASAR geocoding capability at DLR. In: Proc. of ENVISAT and ERS Symposium, Salzburg, Austria.

Hueso González, J., Walter Antony, J.M., Bachmann, M., Krieger, G., Zink, M., Schrank, D., Schwerdt, M., 2012. Bistatic system and baseline calibration in TanDEM-X to ensure the global digital elevation model quality. ISPRS Journal of Photogrammetry and Remote Sensing, 73, pp. 3-11.

Li, J., Chen, W., 2005. A rule-based method for mapping Canada's wetlands using optical, radar and DEM data. International Journal of Remote Sensing, 26, pp. 5051-5069.

Liebe, J.R., Van De Giesen, N., Andreini, M.S., Steenhuis, T.S., Walter, M.T., 2009. Suitability and limitations of ENVISAT ASAR for monitoring small reservoirs in a semiarid area. IEEE Transactions on Geoscience and Remote Sensing, 47, pp. 15361547.

Mahamane, A., Morou, B., Zaman-Allah, M., Saadou, M., Saley, K., Bakasso, Y., Wata, I.S., Oumani, A.A., Jauffret, S., 2012. Climate Variability in Niger: Potential Impacts on Vegetation Distribution and Productivity. Journal of Environmental Science and Engineering B 1, 1, pp. 49-57.

Meier, E., Frei, U., Nüesch, D., 1993. Precise Terrain Corrected Geocoded Images. In: Schreier G. (Ed.): SAR Geocoding and Systems. Wichmann, Karlsruhe, pp. 173-186.

Moreira, A., 1991. Improved Multilook Techniques Applied to SAR and SCANSAR Imagery. IEEE Transactions on Geosciences and Remote Sensing, 29(4), pp. 529-534.

Moser, L., Voigt, S., Schoepfer, E., Palmer, S., 2014. Multitemporal wetland monitoring in sub-Saharan West-Africa using medium resolution optical satellite data. IEEE Journal of Selected Topics in Applied Earth Observations and Remote Sensing, 7, pp. 3402-3415.

Munyaneza, O., Wali, U.G., Uhlenbrook, S., Maskey, S., Mlotha, M.J., 2009. Water level monitoring using radar remote sensing data: Application to Lake Kivu, central Africa. Physics and Chemistry of the Earth, 34, pp. 722-728.

O'Grady, D., Leblanc, M., Gillieson, D., 2011. Use of ENVISAT ASAR Global Monitoring Mode to complement optical data in the mapping of rapid broad-scale flooding in Pakistan. Hydrology and Earth System Sciences, 15, pp. 34753494.
Olson, D.M., Dinerstein, E., Wikramanayake, E.D., Burgess, N.D., Powell, G.V.N., Underwood, E.C., D'amico, J. a., Itoua, I., Strand, H.E., Morrison, J.C., Loucks, C.J., Allnutt, T.F., Ricketts, T.H., Kura, Y., Lamoreux, J.F., Wettengel, W.W., Hedao, P., Kassem, K.R., 2001. Terrestrial Ecoregions of the World: A New Map of Life on Earth. Bioscience, 51(11), pp. 933-938.

Raggam, H., Gutjahr, K., 2004. Generation of Layover/Shadow Mask (GIM Product). Technical Note, Joanneum Research, Graz, Austria.

Rosenqvist, A., Finlayson, M.C., Lowry, J., Taylor, D., 2007. The potential of long-wavelength satellite-borne radar to support implementation of the Ramsar Wetlands Convention. Aquatic Conservation: Marine and Freshwater Ecosystems, 17, pp. 229-244.

Santoro, M., Wegmüller, U., Lamarche, C., Bontemps, S., Defourny, P., Arino, O., 2015. Strengths and weaknesses of multi-year Envisat ASAR backscatter measurements to map permanent open water bodies at global scale. Remote Sensing of Environment, 171, pp. 185-201.

Schmitt, A., 2012. Änderungserkennung in multitemporalen und multipolarisierten Radaraufnahmen. PhD dissertation, Karlsruhe Institute of Technology (KIT), Karlsruhe, Germany.

Schmitt, A., Wendleder, A., Hinz, S., 2015. The Kennaugh element framework for multi-scale, multi-polarized, multitemporal and multi-frequency SAR image preparation. ISPRS Journal of Photogrammetry and Remote Sensing, 102, pp. 122139.

Westerhoff, R.S., Kleuskens, M.P.H., Winsemius, H.C., Huizinga, H.J., Brakenridge, G.R., Bishop, C., 2013. Automated global water mapping based on wide-swath orbital synthetic-aperture radar. Hydrology and Earth System Sciences, 17, pp. 651-663.

Westra, T., De Wulf, R., Van Coillie, F., Crabbe, S., 2010. Optimal Envisat advanced synthetic aperture radar image parameters for mapping and monitoring Sahelian floodplains. Journal of Applied Remote Sensing, 4, pp. 1-17. 